immunoglobulin G. Biochem. Biophys. Res. Commun., 64: 1310 (1975).

4. Bowman, B. H., Lockhart, L. H., and McCombs, M. L.: Oyster ciliary inhibition by cystic fibrosis factor. Science, 164: 325 (1969).

5. Conference Committee: Progress report on ciliary inhibitor factors, p. 2 (GAP Conference Reports, National Cystic Fibrosis Foundation, 1973).

6. Danes, B. S.: Cystic fibrosis heterozygote detection: a study on a normal population. Clin. Genet., 7: 128 (1975).

7. Danes, B. S., and Bearn, A. G.: Oyster ciliary inhibition by cystic fibrosis culture medium. J. Exp. Med., 136: 1313 (1972).

8. Danes, B. S., Beck, B., and Flensborg, E. W.: Cystic fibrosis heterozygote detection: A family study. Clin. Genet., 8: 85 (1975).

9. Di Sant'Agnese, P. A., and Talamo, R. C.: Pathogenesis and pathophysiology of cystic fibrosis of the pancreas. N. Engl. J. Med., 277: 1287, 1344, 1399 (1967)

10. Doggett, R. G., and Harrison, G. M.: Cystic fibrosis: Reversal of ciliary inhibition in serum and saliva by heparin. Tex. Rep. Biol. Med., 31: 687 (1973).

11. Doggett, R. G., and Harrison, G. M.: Cystic fibrosis: in vivo reversal of the ciliostatic character of serum and parotid secretions by heparin. Cystic fibrosis: in vitro reversal of the ciliostatic character of serum and salivary secretions by heparin. Nature New Biol., 243: 250, 251 (1973).

12. Fisher, E. H., and Stein, E. A.: $\alpha$-Amylase from human saliva. Biochem. Prep., 8: 27 (1961).

13. Gillard, B. K., and Nelson, T. E.: The use of substrate model inhibitors to study the mechanism of action of rabbit muscle amylo-1,6-glucosidase/4- $\alpha$-glucanotransferase. (In preparation.)

14. Kaiser, D., Drack, E., and Rossi, E.: Effect of cystic fibrosis sweat on sodium reabsorbtion by the normal sweat gland. Lancet, $i$ : 1003 (1970).

15. Lowry, O. H., Rosebrough, N. J., Farr, A. L., and Randall, R. J.: Protein measurement with the Folin phenol reagent. J. Biol. Chem., 193: 265 (1951)

16. Mangos, J. A., and McSherry, N. R.: Sodium transport: inhibitory factor in sweat of patients with cystic fibrosis. Science, 158: 135 (1967).

17. Mangos, J. A., McSherry, N. R., and Benke, P. J.: A sodium transport inhibitory factor in the saliva of patients with cystic fibrosis. Pediat. Res., 1:436 (1967).

18. McCombs, M. D.: Research in cystic fibrosis. Tex. Rep. Biol. Med., 3I: 615 (1973).

19. McNeely, C., and Bowman, B. H.: Cystic fibrosis: Is the ciliary inhibitor present in the urine? p. 6 (Cystic Fibrosis Club Abstracts, Denver, 1975).

20. Miller, G. L.: Protein determination for large numbers of samples. Anal. Chem. 31: 964 (1959).

21. Nelson, T. E., Gillard, B. K., and Bishop, S. H.: Salivary $\alpha$-amylase and the role of polyamine binding to carbohydrases in cystic fibrosis ciliostasis, p. 7 (Cystic Fibrosis Club Abstracts, Washington, D.C., 1974).

22. Nelson, T. E., Gillard, B. K., and White, R. C.: The mechanism of action of glycogen debranching enzyme: A catalytically bifunctional protein molecule [Abstract]. Fed. Proc., 33: 1311 (1974).

23. Nelson, T. E., Kolb, E., and Larner, J.: Purification and properties of rabbit muscle amylo-1,6-glucosidase/oligo-1,4-1,4-transferase. Biochemistry, 8: 1419 (1969).

24. Reese, E. T. Parrish, F. W., and Ettlinger, M.: Nojirimycin and D-glucono-1,5lactone as inhibitors of carbohydrases. Carbohyd. Res., 18: 381 (1971).

25. Robyt, J. F., and Whelan, W. J.: The $\alpha$-amylases. In: J. A. Radley: Starch and lts Derivatives, 4th Ed., p. 431 (Chapman and Hall, London, 1968).

26. Spock, A., Heick, H. M. C., Cress, H., and Logan, W. S.: Abnormal serum factor in patients with cystic fibrosis of the pancreas. Pediat. Res., l: 173 (1967).

27. Watts, T. E., and Nelson, T. E.: An improved purification procedure for rabbit muscle amylo-1,6-glucosidase/oligo-1,4 $\rightarrow 1,4$-glucantransferase. Anal. Biochem., 49: 479 (1972).

28. We wish to thank the staffs of the UCLA and TIRR Cystic Fibrosis Centers for assistance in collecting saliva samples. We would also like to thank Drs. Richard Dooley and Alan Osher of the UCLA Cystic Fibrosis Center for continued support during the course of this investigation.

29. The Human Subject Protection Committees at UCLA, TIRR, and Baylor have approved the procedures used for collection of saliva.

30. Dr. B. K. Gillard is a Research Fellow of the National Cystic Fibrosis Research Foundation.

31. This work was supported in part by grants from the United States Public Health Service, National Institutes of Health Grants nos. AM-17524 and RR 5354.

32. Requests for reprints should be addressed to: T. E. Nelson, Ph.D., Department of Rehabilitation, Baylor College of Medicine, Houston, Tex. 77030 (USA).

33. Accepted for publication May 4, 1976.

\title{
The Rate of Cerebral Utilization of Glucose, Ketone Bodies, and Oxygen: A Comparative in Vivo Study of Infant and Adult Rats
}

\author{
G. DAHLQUIST ${ }^{(39)}$ AND B. PERSSON
}

Department of Pediatrics, Karolinska Institutet, St. Göran's Children's Hospital, Stockholm, Sweden

\section{Extract}

Cerebral blood flow (CBF) was measured by means of ${ }^{141} \mathrm{Ce}-$ labeled microspheres in infant (20-day-old) and adult (3-monthold) rats, anesthetised with Na-5-ethyl-5-(1-methylpropyl)2-thiobarbituric acid. Cerebral arteriovenous differences of acetoacetate, D- $\beta$-hydroxybutyrate, glucose, lactate, and oxygen and brain DNA content were determined in other groups of similarly treated infant and adult animals fed or starved for 48 or $72 \mathrm{hr}$.

The mean $\mathrm{CBF}$ values of $0.48 \pm 0.04$ and $0.62 \pm 0.07 \mathrm{ml} /(\mathrm{g} \times$ $\min ), \pm \mathrm{SEM}$, in infant and adult animals, respectively, were not significantly different. CBF was unaffected by starvation.

At any given arterial concentration the cerebral arteriovenous difference of acetoacetate was significantly higher in infant than adult rats. The same was true for $D$ - $\beta$-hydroxybutyrate at arterial concentrations above $1 \mathrm{mmol} /$ liter. There was an approximately linear relationship between arterial concentration of acetoacetate and its cerebral arteriovenous difference in both infant and adult rats. A similar relationship was found for $D$ - $\beta$-hydroxybutyrate only in infant animals.

In the fed state, the cerebral uptake of glucose and ketone bodies (micromoles per (mg DNA $\times$ min)) was not different in infant and adult rats. During starvation, cerebral uptake of ketone bodies expressed as micromoles per (mg DNA $\times$ min) was higher in infant than adult rats, indicating a higher rate of utilization of ketone bodies per cell in these animals. For glucose, no such difference was found in either fed or starved groups (Table 3 ). The average percentage of the total cerebral uptake of substrates (micromoles per min) accounted for by ketone bodies increased in both infant and adult rats during starvation. This percentage value was clearly 
higher in infant than adult rats during starvation. After 72 hr of starvation the values were $38.8 \%$ and $15.2 \%$ in infant and adult rats, respectively (Fig. 3).

Calculated cerebral metabolic rate for oxygen $\left(\mathrm{CMRO}_{2}\right)$, assuming complete oxidation of glucose and ketone bodies and expressed as micromoles per $(\mathrm{mg} D \mathrm{DA} \times \min )$, was similar in fed and starved rats of both age groups (Table 3 ), indicating that ketone bodies serve as an alternative substrate for glucose during starvation. Calculated $\mathrm{CMRO}_{2}$ for glucose plus ketone bodies was similar to the measured $\mathrm{CMRO}_{2}$ in adult rats both in the fed and the starved groups. For infant rats, calculated $\mathrm{CMRO}_{2}$ for glucose plus ketone bodies was higher than measured $\mathrm{CMRO}_{2}$, indicating that in this age group a portion of substrate was used for synthesis or storage rather than for complete oxidation.

\section{Speculation}

The present study supports the concept that during the period of maximum myelination in rat brain, when the need of substrate for synthesis of lipid and protein is great, the infant rat brain is adapted to a higher utilization of $D$ - $\beta$-hydroxybutyrate and acetoacetate than later on in life. Thus, during starvation when glucose supply is limited but acetoacetate and $D$ - $\beta$-hydroxybutyrate are available, the synthesis of myelin could be preserved.

In the rat, the capacity to utilize ketone bodies in different organs changes during maturation. Thus the activities of the enzymes involved in ketone body catabolism, i.e.. D- $\beta$-hydroxybutyrate dehydrogenase (EC. 1.1.1.30), 3-oxo-acid-CoA-transferase (EC. 2.8.3.5), and acetoacetyl-CoA-thiolase (EC. 2.3.1.9) are low in the kidneys and heart of the infant rat but gradually increase to reach adult values at approximately 5 weeks of age $(18,19)$. In the brain. however, the activity of acetoacetyl-CoA-thiolase is higher in infant rats from birth and throughout the suckling period compared with that in adult animals (21). The activities of D- $\beta$-hydroxybutyrate dehydrogenase and 3-oxo-acid-CoA-transferase in rat brain are comparable with adult levels at birth, increase several fold during the suckling period to reach a maximum at 20 days of age, after which they gradually decline $(7,17,21)$.

In vitro studies have shown that when brain slices of 5-day-old rats were incubated with glucose or acetoacetate, the oxygen consumption increased equally with either substrate (10). Furthermore, the formation of acetyl-coenzyme A occurred more readily from acetoacetate or DL- $\beta$-hydroxybutyrate than from glucose in cerebral cortex slices from infant rats. This was in contrast to findings in adult rat brain (14).

In vivo studies have disclosed higher cerebral arteriovenous differences of $D$ - $\beta$-hydroxybutyrate and acetoacetate in infant than in adult rats at the same arterial concentrations, whereas arteriovenous differences of glucose were the same (13). The utilization rates of glucose and ketone bodies by the brain of 18-day-old rats have recently been assessed during compartmental analysis of isotopic data (6). Similar studies have not been performed in adult rats.

The purpose of the present study was to compare the rate of cerebral utilization of oxygen, glucose, acetoacetate, and $D$ - $\beta$-hydroxybutyrate in infant and adult rats in vivo and to determine the influence of starvation on the relative proportion of glucose and ketone bodies used by the brain. Estimations of the rate of cerebral utilization of substrates were based on measurements of cerebral blood flow and the cerebral arteriovenous differences.

\section{MATERIALS AND METHODS}

\section{STUDY PROTOCOL}

A total of 33 adult (3-month-old) female rats and 46 infant (20-day-old) rats of both sexes of the Sprague-Dawley strain were used. The animals were kept at an environmental temperature of $2225^{\circ}$, had free access to water, and were fed a commercial rat chow (32) when not starved. Cerebral blood flow was measured in 11 adult and 14 infant rats. These groups will be referred to as $C B F$ groups. CBF was also measured in four adult and six infant rats after $48 \mathrm{hr}$ of starvation. Cerebral arteriovenous differences of acetoacetate, D- $\beta$ hydroxybutyrate, glucose, lactate, and oxygen were studied in 22 adult rats, 9 of which were fed, 6 starved for $48 \mathrm{hr}$, and 7 starved for $72 \mathrm{hr}$; and in 22 infant rats, 7 of which were fed, 7 starved for $48 \mathrm{hr}$, and 8 starved for $72 \mathrm{hr}$. These groups will be referred to as cerebral arteriovenous difference $C(a-v)$ groups.

All rats were anesthetized with an intraperitoneal injection of Na-5-ethyl-5-(1-methylpropyl)-2-thiobarbituric acid (33) in a dose of $80 \mathrm{mg} / \mathrm{kg}$ body weight. The rats were tracheotomized and put on a heating pad, rectal temperature being kept at $36.5-37.5^{\circ}$. A catheter was introduced via the right axillary artery and placed with its tip at or immediately inside the aortic valves. The exact position of the catheter was checked by inspection when the animal was killed. Each experiment was started by drawing an arterial blood sample for immediate analysis of $\mathrm{pH}$ and $\mathrm{pCO}_{2}$ using the Astrup technique and a radiometer equipment (34). Animals with $\mathrm{pCO}_{2}$ exceeding 50 $\mathrm{mm} \mathrm{Hg}$ were excluded.

\section{MEASUREMENT OF CEREBRAL BLOOD FLOW}

Cerebral blood flow was measured with labeled microspheres according to the technique originally described by Rudolph and Heymann (25). ${ }^{141} \mathrm{Ce}-$ labeled carbonized microspheres were obtained from $3 \mathrm{M}$ Co., St. Paul, Minn., and stored in a saline solution containing a detergent (Tween 80). A sphere size of $35 \pm 5 \mu \mathrm{m}$ was selected as these spheres were found to be completely trapped in the brain vessels, whereas smaller spheres $(15 \pm 5 \mu \mathrm{m})$ were recovered in significant amounts in cerebral venous blood samples. Immediately before use, the batch of spheres were sonicated for $5 \mathrm{sec}$ at $20 \mathrm{kHz}$ (35). The saline solution was discarded after sedimentation of the spheres. The microspheres were then mixed with $0.1 \mathrm{ml}$ heparinized rat blood and injected during approximately $25 \mathrm{sec}$ into the axillar catheter under continuous rolling of the syringe. Simultaneously, a reference sample was drawn at a constant rate of $0.3 \mathrm{ml} / \mathrm{min}$ from a catheter in the left femoral artery using a continuous infusion apparatus (36).

The animal was killed by decapitation and the brain, including the cerebellum, was removed and immediately weighed. The brain, reference sample, injection syringe, and catheters were counted separately in a scintillation counter of the well type (37).

If the spheres are evenly mixed at the injection site, they behave as blood particles but are trapped in the capillary system. The flow to an organ can be calculated according to the formula: Blood flow $(\mathrm{ml} / \mathrm{min})=[$ (number of microspheres in organ $\times 0.3) /($ number of microspheres in arterial sample)] (19). Any blood or tissue sample counted containing less than 400 microspheres was excluded for statistical reasons (2).

\section{MEASUREMENT OF CEREBRAL ARTERIOVENOUS DIFFERENCES}

A small hole was drilled in the skull above the confluence of the sagittal and the transverse sinuses. The dura was penetrated with an injection needle and venous blood was sampled with a heparinized syringe ensuring a minimum of air contamination. Arterial blood was drawn simultaneously from the catheter in the axillary artery. Aliquots of $50 \mu \mathrm{l}$ were collected in microcapillars, which thereafter were sealed at both ends, stored on ice, and analyzed for oxygen content within $20 \mathrm{~min}$. Ten microliters of each blood sample were immediately deproteinized with ice-cold perchloric acid for later analysis of lactate. Aliquots of blood were also taken for determination of hemoglobin. The rest of the blood samples were stored in ice 
water and centrifuged within $15 \mathrm{~min}$. The plasma was stored at $-22^{\circ}$ until analyzed for glucose, D- $\beta$-hydroxybutyrate, and acetoacetate. Acetoacetate was always analyzed within $72 \mathrm{hr}$. After decapitation of the rats, the brain was removed, weighed, and stored frozen until analyzed for DNA content.

\section{CHEMICAL ANALYSES}

Oxygen content was analyzed as earlier reported (23). Enzymatic micromethods were used for analysis of plasma acetoacetate and D- $\beta$-hydroxybutyrate (22), glucose (29), and lactate (5). Extraction of DNA from the brain was performed according to the method of Zamenhof et al. (31) and DNA was measured according to the method of Burton (4) as modified by Zamenhof et al. (31).

\section{CALCULATIONS}

To estimate cerebral uptake of substrates, mean cerebral blood flow (milliliters per min) obtained from the CBF groups was multiplied with the mean whole blood value for arteriovenous difference of each of the substrates determined in the $\mathrm{C}(\mathrm{a}-\mathrm{v})$ groups. These calculations were based on the following formulas for expected means $(E)$ and variances $(V)$ of the product: $\mathrm{E}(\mathrm{A} \times \mathrm{B})=\mathrm{E}(\mathrm{A}) \times \mathrm{E}(\mathrm{B}) ; \mathrm{V}(\mathrm{A} \times \mathrm{B})=\mathrm{E}^{2}(\mathrm{~A}) \times \mathrm{V}(\mathrm{B})$ $+E^{2}(B) \times V(A)+V(A) \times V(B)$, where mean $C B F=E(A)$ and mean arteriovenous difference $=\hat{E}(B)$. Degrees of freedom = $\mathrm{n}_{\mathrm{A}_{1}}+\mathrm{n}_{\mathrm{B}_{1}}-2+\mathrm{n}_{\mathrm{A}_{2}}+\mathrm{n}_{\mathrm{B}_{2}}-2$.

As concentrations of acetoacetate, D- $\beta$-hydroxybutyrate, and glucose were measured in plasma, these values had to be transformed to whole blood concentrations. Whole blood and plasma concentrations of acetoacetate, D- $\beta$-hydroxybutyrate and glucose were simultaneously determined in duplicate samples from 10 infant and 10 adult rats fed or starved for 24 to $48 \mathrm{hr}$. From the regression lines thus determined the following formulas were obtained; for infant rats: plasma acetoacetate = $1.26 \times$ whole blood acetoacetate $+0.01(r=0.997)$, plasma $\mathrm{D}$ - $\beta$-hydroxybutyrate $=1.07 \times$ whole blood $\mathrm{D}$ - $\beta$-hydroxybutyr ate $+0.04(r=0.999)$ and plasma glucose $=1.05 \times$ whole blood glucose $+0.10(r=0.984)$; for adult rats: plasma acetoacetate $=$ $1.42 \times$ whole blood acetoacetate $+0.02(r=0.998)$, plasma D- $\beta$-hydroxybutyrate $=1.34 \times$ whole blood D- $\beta$-hydroxybutyrate $+0.01(r=0.996)$, plasma glucose $=1.15 \times$ whole blood glucose $+0.87(r=0.920)$.

\section{STATISTICAL METHODS}

For analysis of cerebral arteriovenous differences and comparison of calculated $\mathrm{CMRO}_{2}$ and measured $\mathrm{CMRO}_{2}$ in the same animal, the paired $t$-test was used. In analysis of the cerebral uptakes of infant and adult rats (Table 3), variances were assumed to be unequal and the approximate $t$-test (28) was used. For all other analyses Student's $t$-test was used. When $P$ was less than 0.05 , differences were considered to be statistically significant.

\section{RESULTS}

\section{BODY WEIGHTS}

Body weights of all animals are listed in Table 1. Mean weight reduction was $20.6 \%$ and $8.4 \%$ in infant and adult animals, respectively, after $48 \mathrm{hr}$ of starvation, and $24.1 \%$ and $14.1 \%$, respectively, after $72 \mathrm{hr}$ of starvation.

\section{BRAIN WEIGHT, BRAIN DNA CONCENTRATION, RECTAL} TEMPERATURE, $\mathrm{pH}$ AND $\mathrm{pCO}_{2}$

Brain weight and brain DNA concentration (Table 1) were unaffected by $72 \mathrm{hr}$ of starvation. The brain DNA concentration was not significantly different between infant and adult rats in either fed or starved groups. Total brain DNA content, however, was significantly higher in adult than in infant rats (Table 1). Mean rectal temperature, mean $\mathrm{pH}$, and mean $\mathrm{pCO}_{2}$ are listed in Table 1. None of these parameters was significantly different between adult animals of the CBF and C(a-v) groups. The same was true for infant animals.

\section{CEREBRAL BLOOD FLOW}

CBF (Table 1), expressed as milliliters per ( $\mathrm{g}$ brain tissue $\times$ $\min$ ), was not significantly different between infant and adult rats. Total CBF (milliliters per min), however, was significantly higher in adult than infant animals. CBF in four adult rats and six infant rats starved for $48 \mathrm{hr}$ was $0.71 \pm 0.12$ and $0.43 \pm 0.06 \mathrm{ml} /(\mathrm{g}$ brain $\times$ min), respectively (mean $\pm \mathrm{SEM}$ ). These values were not significantly different from those of fed animals of either age group.

ARTERIAL CONCENTRATIONS OF PLASMA ACETOACETATE, D- $\beta$-HYDROXYBUTYRATE, GLUCOSE, LACTATE, AND OXYGEN

Arterial concentrations of plasma acetoacetate D- $\beta$-hydroxybutyrate, glucose, lactate, and oxygen are given in Table 2 . The mean arterial concentrations of $\mathrm{D}-\boldsymbol{\beta}$-hydroxybutyrate were significantly higher in infant rats fed or starved for $48 \mathrm{hr}$ compared with those in adult rats. Mean arterial lactate concentration was higher in fed infant than in fed adult rats. However, infant rats had lower arterial lactate concentration than adult rats after $48 \mathrm{hr}$ of starvation. Arterial oxygen content was significantly lower in infant than in adult rats. The same was true for hemoglobin concentrations (Table 1). Calculated oxygen saturation of hemoglobin was approximately 75,73 , and $90 \%$, respectively, in adult rats that had been fed or starved for 48 and $72 \mathrm{hr}$. The corresponding figures were 89,66 , and $63 \%$, respectively, in the infant rat groups. These values for oxygen saturation of hemoglobin corresponds to a $\mathrm{paO}_{2}$ well above $50 \mathrm{~mm} \mathrm{Hg}$ in all groups (9).

\section{CEREBRAL ARTERIOVENOUS DIFFERENCES}

The cerebral arteriovenous difference of acetoacetate was significantly higher in infant than in adult rats both in the fed and starved states (Table 2). The cerebral arteriovenous differene of acetoacetate was also significantly higher in infant than adult rats at corresponding arterial concentrations of acetoacetate (intervals tested: $0-0.3,0.3-0.6$, and $0.6-0.9$ mmol/liter) (Fig. 1). The cerebral arteriovenous difference of $D$ - $\beta$-hydroxybutyrate was significantly higher in starved infant than in starved adult animals (Table 2 ). The relation between the arterial D- $\beta$-hydroxybutyrate concentration and the cerebral arteriovenous difference of $D$ - $\beta$-hydroxybutyrate was approximately linear in infant rats but in adult rats this relation seemed to level off (Fig. 2). At an arterial D- $\beta$-hydroxybutyrate concentration of $1-1.5$ and $1.5-2 \mathrm{mmol} /$ liter, cerebral arteriovenous differences were significantly higher in infant than adult rats at corresponding arterial concentrations $(P<0.05$ and $P$ $<0.01$, respectively). At lower arterial concentrations there was no significant difference. Cerebral arteriovenous differences of glucose were not different between infant and adult rats in either fed or starved groups (Table 2). Significant amounts of lactate were released by the brain in all groups studied. After $48 \mathrm{hr}$ of starvation, cerebral arteriovenous difference of oxygen was significantly lower in infant than in adult rats $(P<0.02)$. Cerebral arteriovenous differences of oxygen was also lower in infant rats starved for $48 \mathrm{hr}$ than in fed infant rats $(P<0.01)$.

\section{CALCULATED CEREBRAL UPTAKE OF DIFFERENT SUBSTRATES}

The calculated cerebral uptake of acetoacetate expressed as micromoles per (mg DNA $\times$ min) was significantly higher in infant than in adult animals after $72 \mathrm{hr}$ of starvation. The calculated uptake of D- $\beta$-hydroxybutyrate was significantly 
Table 1. Cerebral arteriovenous difference $(C(a-v))$ groups and cerebral blood flow (CBF) groups: Body weight, brain weight, rectal temperature, arterial $\mathrm{pH}$ and $\mathrm{pCO}_{2}$, hemoglobin, brain $\mathrm{DNA}$, and $\mathrm{CBF}$ in adult (3-month-old) and infant (20-day-old) rats ${ }^{1}$

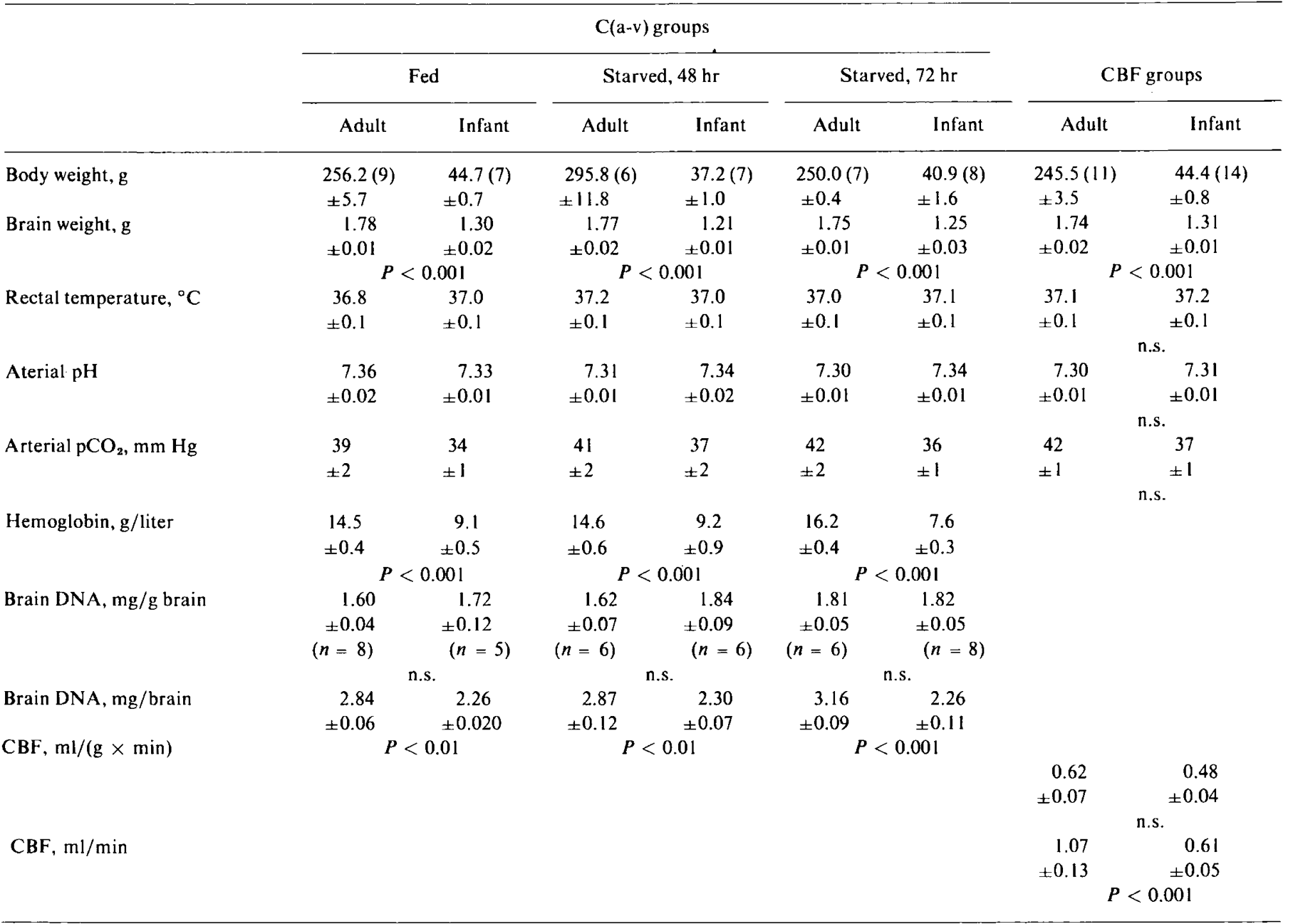

${ }^{1}$ Values are given as mean \pm SEM. Numbers within parentheses denote number of animals. $n$ denotes number of observations, n.s.: not significant.

higher in infant rats starved for both 48 and $72 \mathrm{hr}$ than in adult animals. There was no significant difference between infant and adult animals in cerebral uptake of glucose in either fed or starved animals (Table 3 ).

The determined mean values for total cerebral uptake of ketone bodies and glucose (in micromoles per $\mathrm{min}$ ) were not significantly different between adult and infant rats in either fed or starved groups (Fig. 3). The mean values for fed animals were not significantly different from mean values of animals starved for $72 \mathrm{hr}$ in either adult or infant groups. During starvation the average percentage of the total substrate uptake accounted for by ketone bodies increased in both adult and infant animals (Fig. 3). This percentage value was clearly higher in infant than in adult rats; after $72 \mathrm{hr}$ of starvation the values were $38.8 \%$ and $15.2 \%$, respectively.

\section{CALCULATED AND MEASURED CEREBRAL METABOLIC RATE FOR OXYGEN $\left(\mathrm{CMRO}_{2}\right)$}

Calculated $\mathrm{CMRO}_{2}$, assuming complete oxidation of glucose and ketone bodies, and measured $\mathrm{CMRO}_{2}$ expressed as micromoles $/(\mathrm{mg}$ DNA $\times \mathrm{min})$ are given in Table 3 . The calculated $\mathrm{CMRO}_{2}$ value attributable to ketone bodies was $27.3 \%$ and $39.1 \%$ of the calculated total oxygen consumption in infant rats starved for 48 and $72 \mathrm{hr}$, respectively, and $18.4 \%$ and $16.7 \%$ in starved adult rats, respectively. The calculated $\mathrm{CMRO}_{2}$ values attributable to ketone bodies were significantly higher in starved infant than in starved adult rats. However, no significant differences were found for calculated $\mathrm{CMRO}_{2}$ due to glucose when comparing infant with adult rats of either fed or starved groups. Calculated $\mathrm{CMRO}_{2}$ due to the sum of ketone bodies and glucose was significantly higher than the measured $\mathrm{CMRO}_{2}$ in starved infant rats $(P<0.01$ and $P<0.001$ after 48 and $72 \mathrm{hr}$ starvation, respectively). The measured and calculated $\mathrm{CMRO}_{2}$ values in adult rats fed or starved were about identical. In groups starved for $48 \mathrm{hr}$ the measured $\mathrm{CMRO}_{2}$ was significantly higher in adult than in infant rats. The measured $\mathrm{CMRO}_{2}$ in infant rats was significantly higher $(P<0.02)$ in fed animals than in animals starved for $48 \mathrm{hr}$.

\section{DISCUSSION}

In the present study CBF was determined using radioactive microspheres as this technique is suitable for flow measurements in small animals. Published reports on CBF in rats must be cautiously evaluated as results are dependent on the type of anesthesia and the technique used for blood flow measurements. Thus, Norberg and Siesjö (20), using a ${ }^{133} \mathrm{Xe}$ modification of the Kety and Schmidt principle, reported an average $\mathrm{CBF}$ value of $1.37 \mathrm{ml} /(\mathrm{g} \times \mathrm{min})$ in adult rats $(20)$. In that study the rats were lightly anesthetized with nitrous oxide and the flow measured represented cortical flow which is higher than that of other structures in the rat brain (11). Goldman and Sapirstein (11), using an indicator-fractionation technique, reported CBF values varying between 0.77 and $1.06 \mathrm{ml} /(\mathrm{g} \times$ min) in different structures of the brain of conscious adult rats 
Table 2. Arterial (a) concentrations (millimoles per liter) and cerebral arteriovenous differences $(a-\nu)$ of acetoacetate, $D-\beta$ hydroxybutyrate, glucose, lactate, and oxygen in adult (3-month-old) and infant (20-day-old) rats ${ }^{1}$

\begin{tabular}{|c|c|c|c|c|c|c|}
\hline & \multicolumn{2}{|c|}{ Fed } & \multicolumn{2}{|c|}{ Starved $48 \mathrm{hr}$} & \multicolumn{2}{|c|}{ Starved $72 \mathrm{hr}$} \\
\hline & Adult & Infant & Adult & Infant & Adult & Infant \\
\hline \multirow[t]{2}{*}{ a acetoacetate } & $0.116 \pm 0.021(9)$ & $0.105 \pm 0.010(7)$ & $0.306 \pm 0.039(6)$ & $0.404 \pm 0.048(7)$ & $0.625 \pm 0.039(7)$ & $0.577 \pm 0.094(8)$ \\
\hline & \multicolumn{2}{|c|}{ n.s. } & \multicolumn{2}{|c|}{ n.s. } & \multicolumn{2}{|c|}{ n.s. } \\
\hline \multirow[t]{2}{*}{ a-v acetoacetate } & $-0.019 \pm 0.004(9)$ & $-0.043 \pm 0.005(7)$ & $-0.043 \pm 0.011(6)$ & $-0.098 \pm 0.017(7)$ & $-0.053 \pm 0.009(7)$ & $-0.242 \pm 0.048(8)$ \\
\hline & \multicolumn{2}{|c|}{$P<0.001$} & \multicolumn{2}{|c|}{$P<0.05$} & \multicolumn{2}{|c|}{$P<0.002$} \\
\hline \multirow[t]{2}{*}{ a D- $\beta$-hydroxybutyrate } & \multirow{2}{*}{\multicolumn{2}{|c|}{$P<0.01$}} & \multirow{2}{*}{\multicolumn{2}{|c|}{$P<0.01$}} & \multirow{2}{*}{\multicolumn{2}{|c|}{ (1908) }} \\
\hline & & & & & & \\
\hline \multirow[t]{2}{*}{ a-v D- $\beta$-hydroxybutyrate } & $-0.053 \pm 0.013(9)$ & $-0.047 \pm 0.008(7)$ & $-0.080 \pm 0.015(6)$ & $-0.234 \pm 0.052(7)$ & $-0.087 \pm 0.014(7)$ & $-0.330 \pm 0.044(8)$ \\
\hline & \multicolumn{2}{|l|}{ 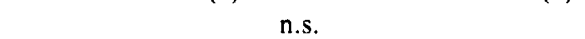 } & \multicolumn{2}{|c|}{$P<0.05$} & \multicolumn{2}{|c|}{$P<0.001$} \\
\hline \multirow[t]{2}{*}{ a glucose } & \multirow{2}{*}{\multicolumn{2}{|c|}{ 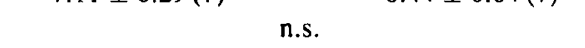 }} & $7.60 \pm 0.73(5)$ & $6.80 \pm 0.66(6)$ & $7.13 \pm 0.30(7)$ & $6.72 \pm 0.29(6)$ \\
\hline & & & \multicolumn{2}{|r|}{ 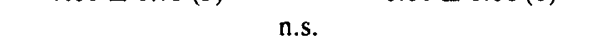 } & \multicolumn{2}{|l|}{ - } \\
\hline a-v glucose & \multicolumn{2}{|l|}{ - } & \multicolumn{2}{|r|}{ - } & \multicolumn{2}{|l|}{ (2) } \\
\hline \multirow[t]{2}{*}{ a lactate } & $0.85 \pm 0.16(8)$ & $1.70 \pm 0.14(6)$ & $1.51 \pm 0.27(3)$ & $0.94 \pm 0.07(5)$ & $0.61 \pm 0.16(7)$ & $0.91 \pm 0.13(5)$ \\
\hline & \multicolumn{2}{|c|}{$P<0.01$} & \multicolumn{2}{|c|}{$P<0.05$} & \multicolumn{2}{|c|}{ n.s. } \\
\hline \multirow[t]{2}{*}{ a-v lactate } & $+0.16 \pm 0.03(6)$ & $+0.43 \pm 0.13(6)$ & $+0.56 \pm 0.32(4)$ & $+0.12 \pm 0.04(5)$ & $+0.09 \pm 0.02(7)$ & $+0.12 \pm 0.06(5)$ \\
\hline & \multicolumn{2}{|c|}{ n.s. } & \multicolumn{2}{|c|}{ n.s. } & \multicolumn{2}{|c|}{ n.s. } \\
\hline a $\mathrm{O}_{2}$ content & $6.75 \pm 0.25(7)$ & $5.05 \pm 0.10(5)$ & $6.64 \pm 0.74(5)$ & $3.73 \pm 0.23(6)$ & $9.10 \pm 0.87(7)$ & $2.99 \pm 0.48(4)$ \\
\hline & & & & & & \\
\hline a-v $\mathrm{O}_{2}$ content & $-2.71 \pm 0.27(7)$ & $-2.97 \pm 0.08(5)$ & $-2.61 \pm 0.16(5)$ & $-1.98 \pm 0.16(6)$ & $-2.97 \pm 0.53(5)$ & $-1.84 \pm 0.58(4)$ \\
\hline & & & & & & \\
\hline
\end{tabular}

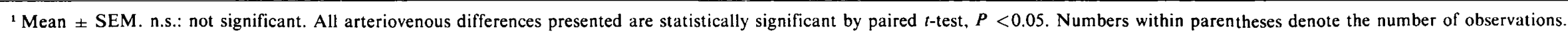
Cerebral uptake is indicated by "." and release by "+." 


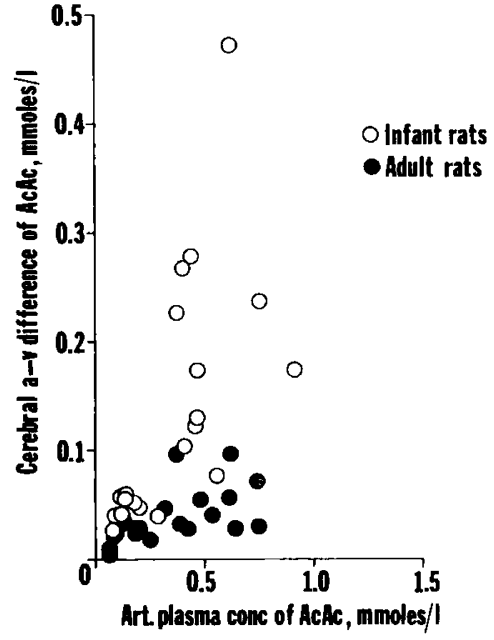

Fig. 1. Arterial concentration (Art. plasma conc) of acetoacetate $(A C A C)$ vs. its cerebral arteriovenous difference in infant (20-day-old) and adult rats.

and between 0.67 and $0.89 \mathrm{ml} /(\mathrm{g} \times \mathrm{min})$ in pentobarbital-anesthetized rats, respectively. Based on measured uptake of $\left[2-{ }^{14} \mathrm{C}\right.$ ]glucose and cerebral arteriovenous difference of glucose, Hawkins et al. (12) have calculated a total CBF value of 0.55 $\mathrm{ml} /(\mathrm{g} \times \mathrm{min})$ in pentobarbital-anesthetized adult rats $(12)$. Our mean CBF value (representing total CBF) of $0.62 \mathrm{ml} /(\mathrm{g} \times$ $\mathrm{min}$ ) in adult rats was thus in good agreement with those previously reported values determined during a similar type of anesthesia. In the present study we had to assume that anesthesia had a similar effect on CBF in infant and adult animals. Starvation for $48 \mathrm{hr}$ did not affect CBF in either infant or adult animals. This was in agreement with the findings of Norberg and Siesjö (20) in adult rats.

Previous studies on the developmental changes in total $\mathrm{CBF}$ in human $(15,26)$ and regional $C B F$ in $\operatorname{dog}(16)$ indicate that during certain periods of development these values are higher than those found in adults. In the present study no such difference was found between 20-day-old infant and adult rats when expressing CBF in $\mathrm{ml} /(\mathrm{g} \times \mathrm{min})$.

As the injected microspheres produce microinfarcts and thus might disturb cerebral metabolism, cerebral arteriovenous differences were determined in other groups of animals. The experiments were designed to minimize differences in factors known to affect $\mathrm{CBF}$ and $\mathrm{CMRO}_{2}$, such as type of anesthesia, rectal temperature, $\mathrm{pH}$, and $\mathrm{pCO}_{2}$. In starved infant rats of the $\mathrm{C}(\mathrm{a}-\mathrm{v})$ groups, however, a moderate hypoxia was present, as reflected by low oxygen saturation values, probably caused by brief respiratory irregularities observed in these rats at the moment of skull puncture. This mild hypoxia with $\mathrm{paO}_{2}$ well above $50 \mathrm{~mm} \mathrm{Hg}$ would not affect cerebral metabolism (27). Neither would CBF have been seriously affected (1).

The mean values for cerebral arteriovenous differences of glucose, lactate, and oxygen in infant and adult rats were in general agreement with those reported by Hawkins et al. (13). Arterial concentrations of acetoacetate and D- $\beta$-hydroxybutyrate were slightly lower in our rats both in fed and starved groups compared with those reported by Hawkins et al. (13). This difference might be due to different rat strains used. However, at a given arterial concentration of acetoacetate and $\beta$-hydroxybutyrate, respectively, cerebral arteriovenous differences were in good agreement with results reported by these authors. At any given arterial concentration of acetoacetate and at arterial concentrations of D- $\beta$-hydroxybutyrate above 1 mmol/liter, cerebral arteriovenous differences were significantly higher in infant than in adult rats, indicating a higher capacity to utilize ketone bodies. In agreement with previous studies $(13,24)$ was the finding of an approximately linear relationship between arterial concentration and cerebral arteriovenous difference of acetoacetate in both infant and adult rats and of a similar relationship between the arterial concentration of $D$ - $\beta$-hydroxybutyrate and its cerebral arteriovenous difference in infant rats. The present finding that this relationship seemed to be nonlinear in the adult rats could indicate either that the transport capacity of $D$ - $\beta$-hydroxybutyrate into the brain was saturated or that the substrate concentration for the rate-limiting enzyme in $D$ - $\beta$-hydroxybutyrate catabolism was close to that for $\mathrm{V}_{\max }$.

It is well documented that the metabolic activity in different parts of the brain differs considerably during development as may regional blood flow. In the present study only total cerebral uptake of different substrates was considered when comparing infant and adult rats. When doing so it seemed reasonable to take into account differences in cell number and therefore the rates of utilization of different substrates were expressed per milligram of DNA. Total brain DNA content in infant and adult rats was in agreement with values reported by Winick (30). The present findings of higher quantitative cerebral uptake of $D$ - $\beta$-hydroxybutyrate and acetoacetate per mg DNA by starving infant rats than by starving adult rats corresponds well with the in vitro findings of a higher capacity to utilize ketone bodies in infant than in adult rat brain $(10,14$, $17,18,21)$. The mean rate of cerebral utilization of glucose was $0.44 \mu \mathrm{mol} /(\mathrm{g}$ brain tissue $\times \mathrm{min})$ in adult rats, which was in reasonable agreement with that given by Hawkins et al. (12) for pentobarbital-anesthetized adult rats. During starvation there was no significant difference in cerebral glucose uptake (per mg DNA and min) between infant and adult animals in the present study. However, in both infant and adult animals, calculated $\mathrm{CMRO}_{2}$ values due to sum of ketone bodies and glucose, assuming complete oxidation and taking into account lactate production, were approximately the same in fed and starved animals. This indicates that ketone bodies serve as alternative substrates for glucose during starvation. This is in agreement with the data of Cremer et al. (6) who found that $\left[2-{ }^{14} \mathrm{C}\right]$ glucose and $\mathrm{D}-3$-hydroxy- $\left[{ }^{14} \mathrm{C}\right]$ butyrate labeled identical pools of tricarboxylate cycle metabolites in the brain of 18-day-old rats.

In adult animals, calculated $\mathrm{CMRO}_{2}$ values due to sum of ketone bodies and glucose were in good agreement with the measured $\mathrm{CMRO}_{2}$. Cerebral arteriovenous difference of oxygen was in agreement with previously reported values $(13,24)$. In infant animals, however, calculated $\mathrm{CMRO}_{2}$ values were significantly higher than the measured $\mathrm{CMRO}_{2}$ in the starved groups and the same tendency was found in fed animals. This could indicate that a portion of substrate was not completely oxidized but was used for synthesis or storage. The calculated oxygen equivalents based on the cerebral arteriovenous differ-

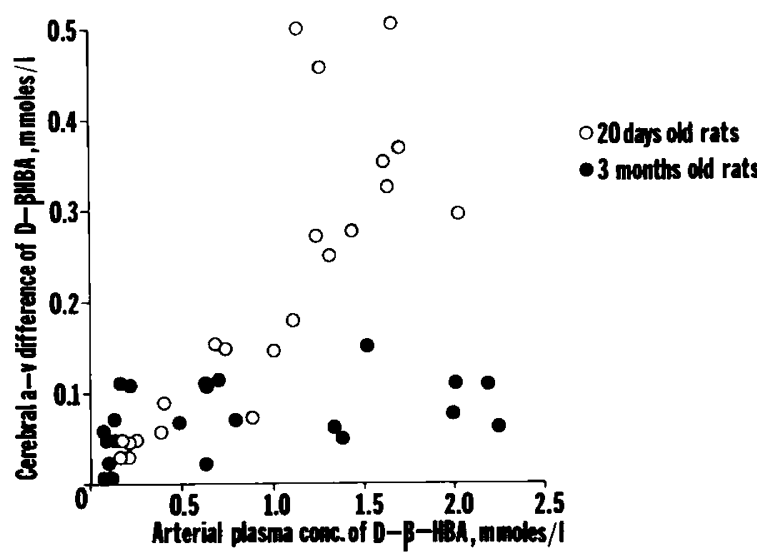

Fig. 2. Arterial concentration of D- $\beta$-hydroxybutyrate $(D-\beta H B A)$ vs. its cerebral arteriovenous difference in infant (20-day-old) and adult rats. 
Table 3. Cerebral uptake (micromoles per $(\operatorname{mg} D N A \times \min )$ ) of acetoacetate $(A c A c),{ }^{1} \beta$-hydroxybutyrate $(H B A),{ }^{1}$ glucose,${ }^{1}$ and oxygen and the calculated oxygen equivalents ${ }^{2}$ due to ketone bodies and glucose in adult (3-month-old) and infant (20-day-old) rats ${ }^{3}$

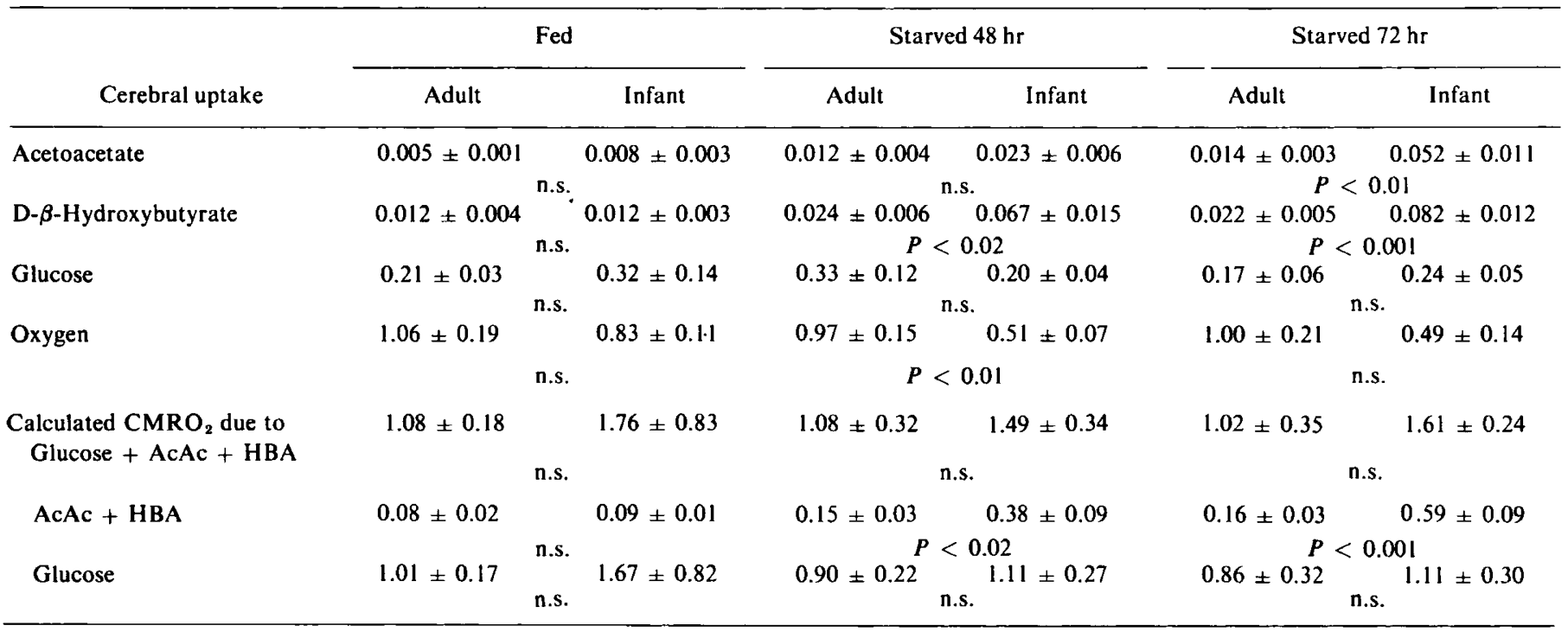

${ }^{1}$ Whole blood values were calculated from plasma values as described in "Materials and Methods" and cerebral uptake by multiplying whole blood a-v difference (milliliter moles per (mg DNA $\times$ milliliter)) by cerebral blood flow (milliliters per min) and using statistical formulas given in "Methods."

${ }^{2}$ The amount of oxygen necessary for complete oxidation of ketone bodies was calculated using the formula $(4.5 \times(\mathrm{HBA})+4.0 \times(\mathrm{AcAc}))$ and for glucose using $6 \times\left(\right.$ glucose $\left.-\frac{\text { lactate }}{2}\right)$.

${ }^{3}$ Values are given as mean \pm SEM. ns.: not significant.

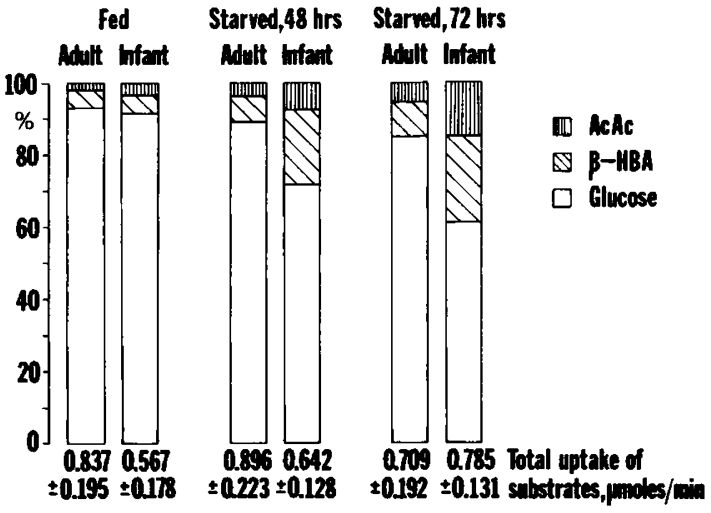

Fig. 3. Cerebral uptake of acetoacetate $(A C A C), D-\beta$-hydroxybutyrate $(\beta-H B A)$, and glucose in adult and infant (20-day-old) rats fed or starved for 48 or $72 \mathrm{hr}$. The values are expressed as a percentage of total substrate uptake in micromoles per min.

ences of substrates were in agreement with values earlier reported for infant rats (13). A similar discrepancy between calculated and measured $\mathrm{CMRO}_{2}$ has recently been found in children under 1 year but not in older children or adults (26). These observations could indicate an age-dependent difference in cerebral metabolism. However, it can not be excluded that such a difference in cerebral metabolism might be related to age-dependent differences in sensitivity to anesthesia.

In infant rats, measured $\mathrm{CMRO}_{2}$ was significantly decreased during starvation. This might either be interpreted as a part of the metabolic adjustment to starvation or again as reflecting a different sensitivity to anesthesia during starvation in this age group.

Reported activities of acetoacetyl-CoA synthetase (acetoacetate-CoA ligase) and acetoacetyl-CoA-thiolase, the two enzymes that catalyze the transfer of acetoacetate via acetoacetyl-CoA to acetyl-CoA, were high in suckling rat brain cytosol (3), indicating a direct pathway for utilization of acetoacetate for fatty acid and cholesterol synthesis in the cytosol. Furthermore, D- $\beta$-hydroxybutyrate has been shown to be a major precursor of amino acid synthesis in infant (15-day-old) rat brain (8).

The present study gives additional support to the concept that at 20 days of age when the rate of myelination in rat brain reaches a maximum and substrate need for lipid and protein synthesis is great, the infant rat brain is adapted to a higher utilization of $D$ - $\beta$-hydroxybutyrate and acetoacetate than the adult rat. Thus, during starvation when glucose supply is limited but acetoacetate and D- $\beta$-hydroxybutyrate are available, myelin synthesis could be preserved.

\section{SUMMARY}

Cerebral blood flow expressed as milligrams per $(\mathrm{g} \times \mathrm{min})$ was similar in infant (20-day-old) and adult (3-month-old) rats. During starvation, the average percentage of the total cerebral uptake of substrate (expressed as micromoles per min) accounted for by ketone bodies increased in both infant and adult rats. This percentage value was clearly higher in infant than adult animals. Cerebral uptake of ketone bodies expressed as micromoles per $(\mathrm{mg}$ DNA $\times$ min) was significantly higher in infant than adult rats during starvation, indicating a higher rate of utilization of ketone bodies per cell in these animals. No such difference was found for glucose in either fed or starved groups. Calculated cerebral oxygen consumption, assuming complete oxidation of glucose and ketone bodies, was similar in fed and starved animals of both age groups and thus ketone bodies might serve as alternative substrates for glucose during starvation. In the infant rats, calculated $\mathrm{CMRO}_{2}$ was higher than measured $\mathrm{CMRO}_{2}$, indicating that in these rats a portion of the substrate was not completely oxidized but was used for synthesis or storage.

\section{REFERENCES AND NOTES}

1. Borgström, L., Jóhannsson, H., and Siesjö, B. K.: The relationship between arterial $\mathrm{pO}_{2}$ and cerebral blood flow in hypoxic hypoxia. Acta Physiol. Scand., 93: 423 (1975). 
2. Buckberg, G. D., Luck, J. C., Payne, D. B., Hoffman, J. I. E., Archie, J. P. and Fixler, D. E.: Some sources of error in measuring regional blood flow with radioactive microspheres. J. Appl. Physiol., 31: 598 (1971).

3. Buckley, B. M., and Williamson, D. H.: Acetoacetate and brain lipogenesis: Developmental pattern of acetoacetyl-coenzyme A synthetase in the soluble fraction of rat brain. Biochem. J., 132: 653 (1973).

4. Burton, K.: A study of the conditions and mechanism of the diphenylamine reaction for the colorimetric estimation of deoxyribonucleic acid. Biochem. J., 62: 315 (1956)

5. Cramp, D. G.: Automated enzymatic fluorometric method for the determina tion of pyruvic and lactic acids in blood. J. Clin. Pathol., 21: 17I (1968).

6. Cremer, J. E., and Heath, D. F.: The estimation of rates of utilization of glucose and ketone bodies in the brain of the suckling rat using compartmental analysis of isotopic data. Biochem. J., 142: 527 (1974).

7. Dahlquist, G., Persson, U., and Persson, B.: The activity of D- $\beta$-hydroxybutyrate dehydrogenase in fetal, infant and adult rat brain and the influence of starvation. Biol. Neonate, 20: 40 (1972).

8. DeVivo, D. C., Leckie, M. P., and Agrawal, H. C.: D- $\beta$-Hydroxybutyrate: A major precursor of amino acids in developing rat brain. J. Neurochem., 25: 161 (1975).

9. Dittmer, D. S., and Grebe, R. M. (Eds.): Handbook of respiration, p. 79 National Academy of Sciences, W. B. Saunders Co., Philadelphia, 1958.

10. Drahota, Z., Hahn, P., Mourek, J., and Trojanova, M.: The effect of acetoacetate on oxygen consumption of brain slices from infant and adul rats. Physiol. Bohem. 14: 134 (1965).

11. Goldman, H., and Sapirstein, L. A.: Brain blood flow in the conscious and anesthetized rat. Amer. J. Physiol., 224: 122 (1973).

12. Hawkins, R. A., Miller, A. L., Cremer, J. E., and Veech, R. L.: Measurement of the rate of glucose utilization by rat brain in vivo. J. Neurochem., 23: 917 (1974).

13. Hawkins, R. A., Williamson, D. H., and Krebs, H. A.: Ketone-body utilization by adult and suckling rat brain in vivo. Biochem. J., 122:13(1971).

14. Itoh, T., and Quastel, J. H.: Acetoacetate metabolism in infant and adult rat brain in vitro. Biochem. J., II6: 641 (1970).

15. Kennedy, C.: The cerebral metabolic rate in children. In: S. R. Korey and J. I. Nurnberger: Progress in Neurobiology. I. Neurochemistry, p. 230 (HoeberHarper, New York, 1965).

16. Kennedy, C., Grave, G. D., Jehle, J. W., and Sokoloff, L.: Changes in blood flow in the component structures of the dog brain during postnatal maturation. J. Neurochem., 19: 2423 (1972).

17. Klee, C. B., and Sokoloff, L.: Changes in $D(-)-\beta$-hydroxybutyric dehydrogenase activity during brain maturation in the rat. J. Biol. Chem, 242: 3880 (1967).

18. Lockwood, E. A, and Bailey, E.: The course of ketosis and the activity of key enzymes of ketogenesis and ketone-body utilization during development of the postnatal rat. Biochem. J., I24: 249 (1971).

19. Makowski, E. L., Meschia, G., Droegemueller, W., and Battaglia, F. C. Measurement of umbilical arterial blood flow to the sheep placenta and fetus in utero. Distribution to cotyledons and the intercotyledonary chorion. Cir. Res., 23: 623 (I968).

20. Norberg, K., and Siesjö, B. K.: Quantitative measurement of blood flow and oxygen consumption in the rat brain. Acta Physiol. Scand., 91: I54 (1974).

21. Page, A. M., Krebs, H. A., and Williamson, D. H.: Activities of enzymes of ketone-body utilization in brain and other tissues of suckling rats. Biochem. J. 121: 49 (1971)

22. Persson, B.: Determination of plasma acetoacetate and D- $\beta$-hydroxybutyrate in newborn infants by an enzymatic fluorometric micromethod. Scand. J. Clin. Lab. Invest., 25: 9 (1970).

23. Persson, B., Settergren, G., and Dahlquist, G.: Cerebral arteriovenous difference of acetoacetate and $D$ - $\beta$-hydroxybutyrate in children. Acta Paediat. Scand., 61: 273 (1972).

24. Ruderman, N. B., Ross, P. S., Berger, M., and Goodman, M. N.: Regulation of glucose and ketone-body metabolism in brain of anaesthetized rats. Biochem. J., I38: 1 (1974).

25. Rudolph, A. M., and Heymann, M. A.: The circulation of the fetus in utero: Methods for studying distribution of blood flow, cardiac output and organ blood flow. Circ. Res., 21 : 163 (1967).

26. Settergren, G., Lindblad, B. S., and Persson, B.: Cerebral blood flow and exchange of oxygen, glucose ketone bodies, lactate pyruvate and amıno acids in infants. Acta Paediat. Scand. (In press.)

27. Siesjö, B. K., and Nitsson, L.: The influence of arterial hypoxemia upon labile phosphates and upon extracellular and intracellular lactate and pyruvate concentration in the rat brain. Scand. J. Clin. Lab. Invest., 27: 83 (1971).

28. Snedecor, G. W., and Cochran, W. G.: Statistical methods, p. 114 (The lowa State University Press. Ames, Iowa, 1968.)

29. Stork, H., and Schmidt, F. H.: Mitteilung über eine enzymatische schnellmethode zur bestimmung des blutzuckers in $5 \mu \mathrm{l}$ capillarblut ohne enteiweissung und ohne zentrifugation. Klin. Wschr., 14: 789 (1968)

30. Winick, M.: Nutrition and cell growth. In: M. Winick: Nutrition and Development, o. 87 (John Wiley \& Sons, New York, 1972).

31. Zamenhof, S., Bursztyn, H., Rich, K., and Zamenhof, P. J.: The determination of deoxyribonucleic acid and of cell number in brain. J. Neurochem., 11: 505 (1964).

32. Articimex Co., Stockholm, Sweden.

33. Inactin, Chem. Fabrik Promota, GmbH, Hamburg, Germany.

34. Radiometer, Copenhagen, Denmark.

35. Branson B-12 sonicator, Branson Sonic Power Co., Danbury, Conn.

36. Perfusor no. 8148, B. Braun Melsungen AG Werk Apparatebau, Melsungen, Germany.

37. Packard no. 3320, Packard Instrument Co., Downer's Grove, III.

38. This study was supported by grants from Semper Fund for Nutritional Research, Karolinska Institutet and the Swedish Medical Research Council (Projects nos. 19p-4106 and 19x-3787).

39. Requests for reprints should be addressed to G. Dahlquist, M.D., Department of Pediatrics, Karolinska Institutet, St. Görans Children`s Hospital, Stockholm. Sweden.

40. Accepted for publication May 21, 1976 